\title{
Design Architecture Of An Integrated Student Activities Management System For Higher Education
}

\author{
Azlan Abdul Aziz ${ }^{1}$, Jamaluddin Jasmis ${ }^{2}$, SyamsulAriffin Yahaya ${ }^{3}$, AlyaGeogiana Buja ${ }^{4}$, Noor \\ Afni Deraman ${ }^{5}$, MohdNorHajarHasrol Jono ${ }^{6}$ \\ ${ }^{1236}$ Computer Science Department, FSKM, UniversitiTeknologi MARA Cawangan Melaka, KampusJasin, \\ Malaysia \\ ${ }^{4}$ Computer Technology and Networking Department, FSKM, UniversitiTeknologi MARA Cawangan Melaka, \\ KampusJasin, Malaysia \\ ${ }^{5}$ Information System Department, FSKM, UniversitiTeknologi MARA Cawangan Melaka, KampusJasin, \\ Malaysia
}

Article History: Received: 11 January 2021; Accepted: 27 February 2021; Published online: 5 April 2021

\begin{abstract}
This paper proposes a technological platform that provides a holistic and user-friendly interface for the management of information pertaining to co-curricular activities handled by the student bodies in UniversitiTeknologi MARA Cawangan Melaka (UiTMCM). The handling of any students activities lie in the collective processes of submitting the proposal, securing the budget, getting the approval, promoting and handling the event, collecting feedbacks, reporting and post-mortem discussion. The management of these activities has been a major concern with the involvement of over 100 student clubs that carry out more than 20 events per week that are vying for a budget. Acquiring the approval for the event proposal, tracking the running of the activities and reporting are some of the factors that created a backlog from the management aspect. These procedures require a physical approach. Therefore, an Interactive Student Activities Management System (iSAMS) was designed and developed through the Waterfall methodology as a one-stop centre to help the UiTMCM Student Affairs Division facilitate the management of the students' activities. This web-based system is able to track, display and store all the activities information from the proposal application stage until the end which includes tracking of attendance, progress of the event, collecting feedback, reporting of completed activities, storing supporting documents and generating reports for administrative purposes. All of these are done and managed via a secure, online interface in the Student Affairs Division website without physical presence of the students and the administrators. Even though iSAMS is yet to be completely implemented, the study has great potential in the form of a holistic management of students' co-curricular activities. Going by that, in the end it is hoped that there is going to be a more efficient management of students' co-curricular activities.
\end{abstract}

Keywords: Students Activities, Integrated Management System, Co-curricular Activities, Covid-19, UiTMCM.

\section{Introduction}

Higher Education Institutions (HEI) play a significant role in a country's overall youth growth by developing their character, awareness, experience, expertise and moulding them into a responsible provider to nationbuilding. Understanding the importance of the curriculum and the co-curricular activities are essential and central to the balanced development of future leaders. In essence, through giving equal priority to the enhancement of students' knowledge and the participation of the students in the co-curricular activities, higher education can achieve its purpose [1]. The latest Coronavirus disease (COVID-19) outbreak also has altered the higher educationallandscape on the learning delivery and the students' co-curricular activities. Such students' activities are targeted at strengthening the students' comprehension, developing the students' coping skills, helping them cope with stress, and offering extra opportunities to improve their employability [2,3]. According to the Education Development Master Plan, the actions of the students are seen as one of the essential strategies for realizing the cycle of human resource development. The current handling of the activities of the students has been somewhat demanding if not taxing from the application paperwork, getting approvals right to reporting the events with evidence and details of participation. Although the academic curriculum has its own set of definite control mechanisms, the same cannot be said for co-curricular activities [4]. The handling of students' activities in UiTM Melaka Branch (UiTMCM) is challenging and demanding as it spans over three campuses at distant locations with 120 active students' clubs having more than 30 activities and programs with over 30 pages of documentation for each activity. The paperwork involves the necessary paperwork plus other required supporting documents. All of these need to be prepared by the students' organizer including getting the signature, comments and approval before the submission to the UniversitiTeknbologi MARA Cawangan Melaka (UiTMCM) Student Affairs Division (SAD) office. Such hassle in the current approach pose many risks in which an integration of technology in the form of Integrated Management System can overcome. Reference [5] mentioned in his research that having an integrated management system can help to accelerate and manage the 
student's activities work flow including the proposals, provide tracking of paperwork, reduce redundancy, reduce the turnaround time, minimize errors, improve data collection quality, support quality improvement efforts and reporting.

\section{PURPOSE OF THE STUDY}

Higher education institutions through some e-learning platforms such as Blackboard, Edmodo, Moodle and Schoology [6] provide student information. These platforms allow students to download and search supplementary learning materials, upload their term papers, view postings and announcements from lecturers or course tutors, and review grades and other students related components. However, co-curricular activities do not have this advantage. Currently, there is no available management systems that handle students' co-curricular activities.

This project studied the requirements (user and system) to serve as inputs towards the design and development architecture for the intended co-curricular activities management system that manages all the students' activities. The notion is to integrate the co-curricular activities within an integrated Students' Activities Management System (iSAMS) with analysis, data mining, and announcement features so that the student's involvement in the activities can be monitored and any intervention can be applied when needed or appropriate. University staff should be able to directly access student's academic progress as well as co-curricular activities via a secure online feature in the university's web-based student information management system [7]. The webbased application currently plays a crucial role in the success of any enterprise [8,9]. It has moved away from just static information suppliers to dynamic full-fledged complex systems with multifaceted processes [8]. Reference [7] also pointed out that the design and implementation of an integrated system for managing college activities should replace the current paper record. As such the most important aim of the system's design architecture is to improvise the handling of the co-curricular activities from paper based to technology based. At the same time, this approach can stream line the utilization of the types of activities carried out to avoid replication, manage the budget, have one system for all the distant campuses to use and refer to. This can provide students with appropriate learning experiences in a well-structured process After all, the effectiveness of students' activities depends on effective management systems [10,11].

The objective of iSAMS is to design and develop an integrated management system for the SAD in UiTMCM for maintaining students' activities regarding the existing clubs and event beginning with proposal application, budget allocation, on-site events registration, closure reports and other relevant details. It monitors all the particulars of the activities from the beginning to the end of the program. This information is used for various purposes from reporting, attendance tracking, course progress, completed activities, programs or events. All these are available in the SAD website with the feature of generating different reports and queries as per requests within a secure environment. Presently huge registers and files are needed to maintain data manually about different aspects of the events and activities. Now the SAD office needs a technologically computerized advanced environment for storing data on students' activities and events. The current manual flow is difficult to maintain and almost futile when it comes to large amount of data which is time consuming and costly. The manual approach is a waste of stationery products, human resources, work force effort, and physical storage. It is hoped that with the newly designed and developed computerized and automatic management system environment, all the issues related to the manual approach can be resolved.

Other works by [12], [13] and [14] also pointed to the efficiency, fast processing, time and cost saving features if an integrated management system is used to handle students' activities at the college or higher education institutions.

\section{METHODOLOGY}

The initial work started with a considerable literature search to collect significant information about cocurricular activity management systems and information systems in general. Some existing management platform and information systems were reviewed, evaluated and compared. The general features and structure of these systems were studied and evaluated and whether or not these features can be implemented in the cocurricular activities management system for the SAD in this higher education institution. Such approach of using management information system in planning, controlling, organizing and reporting which is done efficiently and accurately within a short period of time in any organization [15], can surely help the productivity of the organization and ease the management process. The success of each application often relies on how well the application is tailored to the users, needs and experience, and reflects how well the users use it $[16,17,18]$.

This research also used a quantitative approach, in particular descriptive research using personal, guided interviews involving the organizers of co-curricular activities i.e., the students to explore their ideas and thoughts as well as determine the problems they encountered in organizing and managing of the activities. The ideas and 
thoughts gathered were used in the design architecture of the iSAMS. Besides that, the heads of the various units in the SAD and selected personnel (based on their involvement) were also enquired to gather deeper understandings on the flow of the manual handling. This is critical because correct information improves decision-making, increases efficiency and provides a competitive advantage [19]. This include the features and requirements that the future design architecture of iSAMS should be developed and integrated. A study of the latest development tools, techniques and technologies was also conducted to confirm the correct specification of the system are included. All of these are done with the focus of coming up with a beneficial system. Such improved arrangement and management of student activities, taking into account students' preferences and reasons for participation, is necessary [20] to ensure success. This research used the Waterfall Model that consists of five phases such as the Requirements Analysis, Design, Development, Testing and Maintenance (Fig 1).

\section{Phase 1: Data Gathering and Analysis / Information}

The knowledge acquisition and analysis of the background study had been carried out thoroughly for the Integrated Student Activities Management System (iSAMS). The structured and semi-structured approaches of online interviews were conducted with various stakeholders: a group of students, the Student Affairs Division (SAD) personnel and the respective head of units under SAD to complement the knowledge acquisition findings. The purpose of these interviews was to obtain feedback and crucial information from the stakeholders' perspective on the existing approaches that are valuable for this study. These insights proved to be fundamental in order to address the issues related to the current handling and management of students' activities and events. Based on the analyzed requirements, a use case diagram and an activity diagram were drawn to illustrate the flow of the integrated management system proposed in this project.

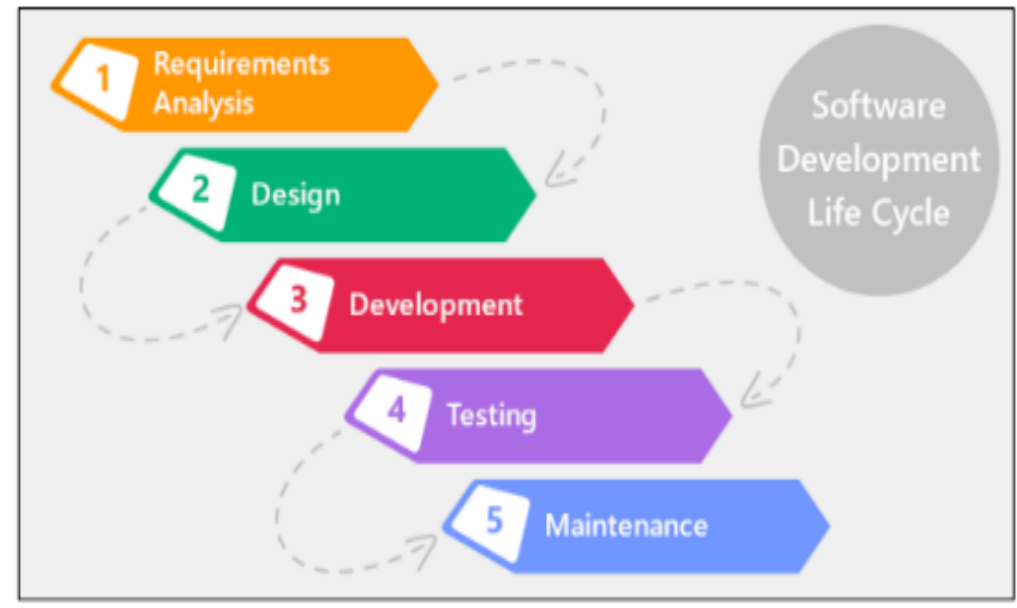

Fig 1: Waterfall Model Phase

\section{Phase 2: Design Phase}

The system architecture was designed according to the gathered requirements. This design phase is deemed important alongside the requirements analysis phase. As soon as the requirements gathering and analysis activities were completed, the design of the system architecture was appropriately generated which consisted of related system components for students' activities and events management process.

\section{Phase 3: Development Phase}

The proposed integrated management system was developed in accordance to the analyzed and design requirements in the development phase. This development is merely a proof of concept and was carried out with the inclusion of the necessary hardware and software. In addition, the development of iSAMS is hoped to help the users to deal more effectively with all the affairs of organizing students' activities and events.

\section{Phase 4: Testing Phase}

This testing phase is considered a make or break phase for iSAMS. The iSAMSwas tested by selected users from the students and the administrative personnel from the SAD on the grounds that the system had been developed according to the intended requirements and specifications. The functionality testing had also been done by the developers.

\section{A. Understanding User and System Requirements}

The important aspect for the design and development of an accurate application or system is understanding the targeted user and system requirements. The researcher managed to identify the user and system requirements presented in Tables 1 and 2. These are from the interviews conducted earlier among the heads of the various units in SAD, its personnel and some students who have handled students' activities before. Table 1 is related to 
the scenarios gathered from the intended target users and used to sketch the database design. Table 1 reports the identified user requirements information and Table 2 reports the summary of identified system requirements from the interviews conducted. The following information performs as inputs in creating the design architecture of the iSAMS.

Table 1: Summary of Identified User Requirements: Student

\begin{tabular}{l} 
User Type: Student as Activity Organizer \\
The system is accessible through a web based-system. \\
The system has notifications on new activities posted by organizers. \\
Notifications receives is based on interests that user have chosen during the \\
registration process. \\
The system has an event reminder to notify users on upcoming activities that the \\
students are required to participate. \\
The system is able to display students that signed-up to the same activity. \\
Registration is required for students to access the system. \\
The system has a separate provision or account/features for event or activity \\
organizers based on a code number provided by the Student Affairs Division \\
personnel (co-curricular activities unit). \\
The system has the feature to disseminate information of new activities to \\
specific target students. \\
The system is able to track participants that are interested in a particular event or \\
activity \\
\hline The system is able to let the participants evaluate the activities in terms of the \\
speaker, the content and the infrastructure (which are relevant) and send \\
feedbacks. \\
The system is able to send updates and notifications to participants. \\
\hline The system is able to accept information details of events and the budget usage \\
(with receipts), for the purpose of closure reporting and post mortem reporting \\
with uploading of supported files and formats e.g., pictures and word processing \\
format
\end{tabular}

Table 2: Summary of Identified User Requirements: System Administrator User Type: System Administrator

The system allows registration and verification of new clubs, organizations,
events and event organizers.
The system can verify activities and events created by clubs, organizations
and event organizers.
The system allows approval of events by the respective authorized personnel.
The system can verify student registration.
The system is able to highlight or display notifications of similar titled events
from any branch campus in UiTMCM.
The system is able to highlight or display notifications of low budget
availability.
The system can generate student's attendance based on events, programs,
campus, semesters and based on specific format.
The system can generate reports with selected details in a specific report
format e.g., for closure or post mortem.
The system allows the creation of new system administrators.

\section{B. Understanding User and System Requirements}

The Model-View-Control (MVC) architectural design was used to develop the integrated Students Activities Management System (iSAMS) that handled all the relevant operations regarding the co-curricular activities. The Model-View-Control (MVC) usually is used for the presentation, business process and data base handling and updating and for easy maintenance. The model-view-controller (Fig 2) consists of three components which are used to define the interaction in the system. The specification design and implementation of the system was created with the understanding gained from the interview conducted.

\section{Model Component}

The model component is considered as the business entity where the application operates. This is where all the data-related to the students' activities in the system are presented. 


\section{View Component}

View component concerns with the user interface of the system. It acts as the communication medium between the system and the user where the user interaction takes place. The files created for the view component are in HTML and JSP file.

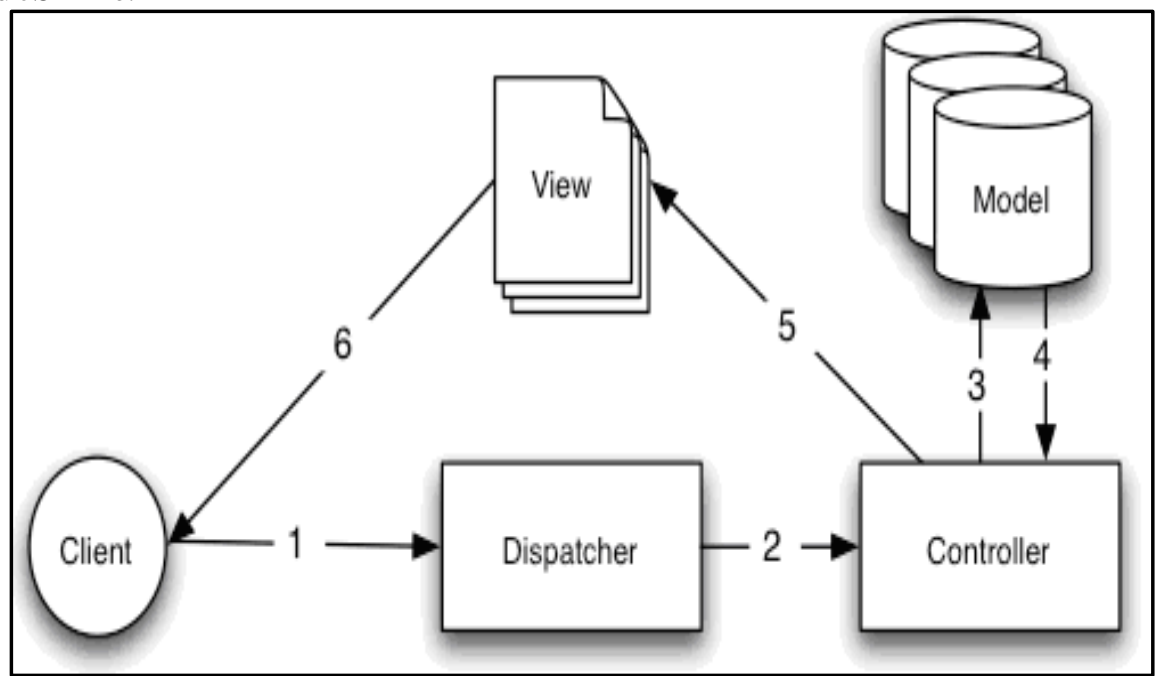

Fig 2: MVC Working Model

\section{Controller Component}

The middle layer, which is the Controller component, acts at the connector between the model and the view component. It handles all the requests made from a view in the view component and updates the model based on the user behaviour. The controller then interacts with the view to generate the output representation to the user based on the request made earlier.

One of the benefits of MVC architecture is that it helps to reduce the complexity in writing the code required because there is a separation between the requests and the pages. This proves to be easier to implement in relation to writing the coding in the proper way based on specification of each part. Fig 3 shows the MVC Architecture Logical Design of the iSAMS. Figure 4 indicates the Entity Relationship Diagram (ERD) for the iSAMS.

The iSAMS is a 3-tier architecture web-based platform that consists of three logical computing layers. This architecture is adopted as the typical platform of a client-server structure. Greater flexibility for developers can be achieved by modularizing the user interface layer, the application logic layer, and the data storage layer. This allowed the development team to update modules independently without affecting other parts which are being worked on by the rest of the team and this decreased the development cycle time.

In this model, the client tier is the web browser. Students and administrators can access the iSAMS web on the desktop. The iSAMS is designed to be a web-based system that works on the computers with Internet access. It can provide students with information about upcoming activities, published by the organizers of the cocurricular activity. Besides that, the iSAMS also allows the students to get the lists of activities and events that match their preferences and interests. In addition, it also shows the students who have signed up for the activities or events.

By accessing their respective accounts, the students' organizer can submit application on organizing new event and activity, make announcements, post upcoming activities or events, updates, handle registration on the day of the activity/event, disseminate information to potential participants, submit details for the closure report on the activity/event, submit details of the budget, submit supporting documents and generate report. All these are done through the student organizer's respective accounts via desktop clients. 


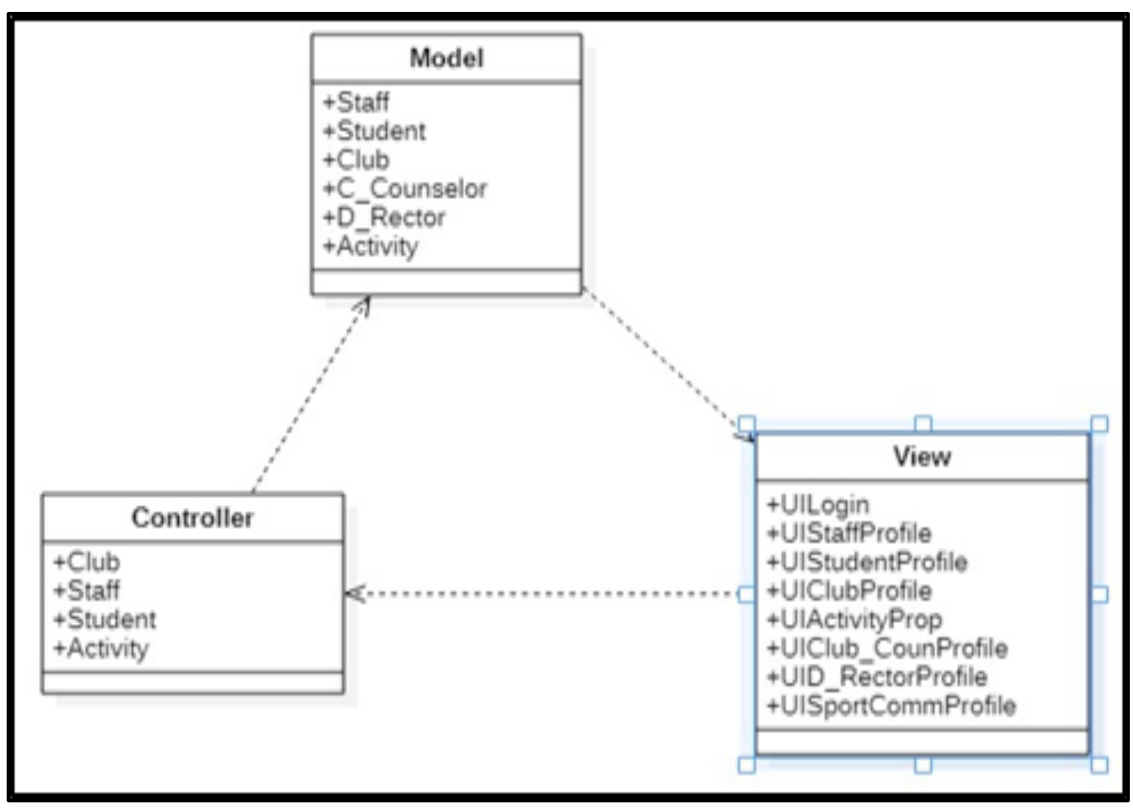

Fig 3: MVC Architecture Logical Design

The application tier does the processing of the dynamic contents and client-database interactions in database tier. It serves as a dynamic gateway and generates dynamic content at the same time. The usual database layer serves as a web-based application database, where the data for the iSAMS and the managing programs for the $\mathrm{read} / \mathrm{write}$ operations to the database are stored.

Fig 4 indicates the Class Diagram in relation to iSAMS MVC design pattern. UML 2.0 that is intended to provide a standard way to visualize the different aspect of a system [21] governs the diagrams' coordination.

\section{IMPLEMENTATION OUTCOMES}

These are some of the significant outcomes of iSAMS even though it is yet to be fully implemented and to be running in full force.

A. Programming Language

The main purpose of the iSAMS is to manage data and handle all the tasks relating to managing students' activity and event. As such the system was designed as a web-based system.

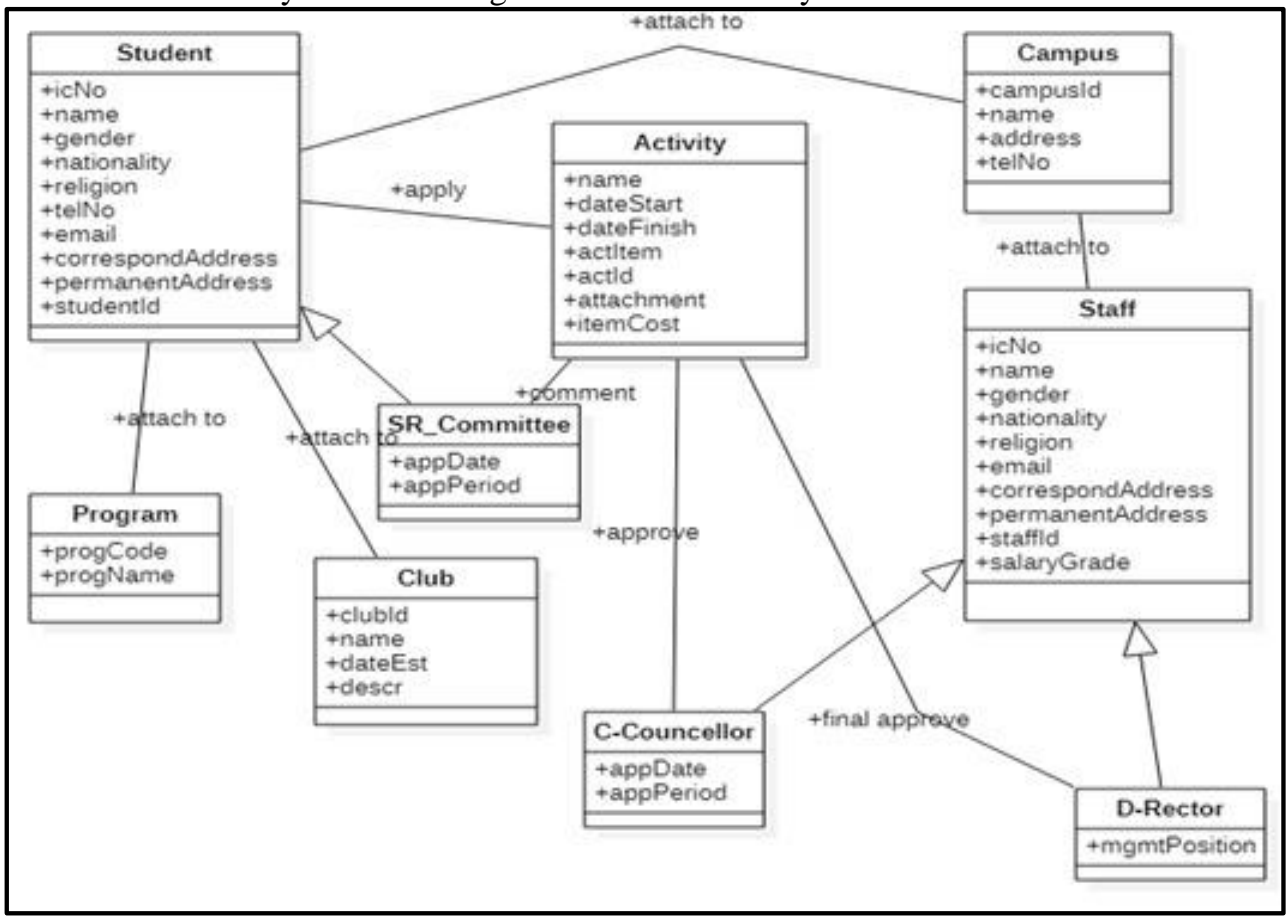

Fig 4: Entity Relationship Diagram 
The languages used to implement the system are Java Server Page (JSP) as front-end language and JAVA as the back-end language. JSP is a language that can create and generate Web pages dynamically, based on XML, HTML and other types of document. The dynamic part of JSP is written in JAVA as it is more powerful and easier to use. JAVA as a programming language has the simultaneous, object-oriented and class-based capability with very few implementation dependencies. JAVA is chosen because it is suitable for any programming task, easy to use and therefore easy to write and debug.

Table 3: User Interface

\begin{tabular}{ll}
\hline $\begin{array}{l}\text { User } \\
\text { Interface }\end{array}$ & Description \\
\hline Login & This page enables the user to login into the iSAMS. \\
\hline Manage Club Profile & $\begin{array}{l}\text { This page allows user to manage the club information } \\
\text { and member including view and update. }\end{array}$ \\
\hline Manage Staff Profile & $\begin{array}{l}\text { This page allows staff to view and update their own } \\
\text { information. }\end{array}$ \\
\hline Manage Student Profile & $\begin{array}{l}\text { This page allows student to update their own } \\
\text { information. }\end{array}$ \\
\hline $\begin{array}{l}\text { Manage Deputy Rector } \\
\text { Profile }\end{array}$ & $\begin{array}{l}\text { This page allows deputy rector to view and update his } \\
\text { own information. }\end{array}$ \\
\hline $\begin{array}{l}\text { Manage Club } \\
\text { Counselor Profile }\end{array}$ & $\begin{array}{l}\text { This page allows club counselor to view and update their } \\
\text { own information. }\end{array}$ \\
\hline $\begin{array}{l}\text { Manage Sport } \\
\text { Committee Profile }\end{array}$ & $\begin{array}{l}\text { This page allows club counselor to view their own } \\
\text { information. }\end{array}$ \\
\hline $\begin{array}{l}\text { Manage Campus } \\
\text { Profile }\end{array}$ & This page allows user to view campus information. \\
\hline $\begin{array}{l}\text { Manage Program } \\
\text { Profile }\end{array}$ & \begin{tabular}{l} 
This page allows user to view program information. \\
\hline $\begin{array}{l}\text { Manage Activity } \\
\text { Proposal }\end{array}$
\end{tabular} \\
\hline
\end{tabular}

The database management system chosen for the iSAMS is the open-source MySQL. This relational database is used by many large corporations' websites handling large amount of data. The compatibility between MySQL and JAVA and JSP is the reason for choosing MySQL besides the MySQL feature of handling a large capacity of data management.

\section{B. User Interface}

The user interface is a medium that enables interaction between humans, i.e., users and computers. The user interface must be user-friendly and attractive for the user. Table 3 depicts a part of the overview of each user interface.

\section{CONCLUSION}

The current manual approach of managing the students' co-curricular activities and events, even though has been in place for years, has many flaws and weaknesses. It does not have the features and characteristics to sustain the ever-demanding challenges and complexities of organizing the data and its processes from the beginning until the end. This has triggered the design and development of the Integrated Student Activities Management System (iSAMS) with the aim of providing a more reliable approach to handling the large amount of data and processes with the aid and support of technology. This study has demonstrated the importance of providing an integrated management information system for the Student Affairs Division to handle its core operation within a higher education institution while manoeuvring the demands of today's processes. The stakeholders, the students and administrators alike can benefit from a more systematic process with the aid of iSAMS in a holistic management approach. It is hoped that this study has presented a design architecture for the systematic development and implementation of the analysis, which represents the conceptual aspect of the proposed system. Once the iSAMS is fully established and implemented, a more rigorous functional testing is to be conducted to ensure the quality and acceptance of the highest standard is achieved. Further recommendation to this system is to prepare a mobile application interface that access the same platform.

\section{ACKNOWLEDGEMENT}

This work was funded by a grant (TEJA 2020) from UniversitiTeknologi MARA Cawangan Melaka (GDT2020-31). 


\section{References}

1. Malaysian Education Blueprint 2013-2025 Pre-School to Post Secondary Education

2. Veronesi, M.C. and Gunderman, R.B. 2012. Perspectives: the potential of student organizations for developing leadership: one school's experience Acad. Med., 87 (2) (2012), pp. 226-229.

3. Thompson, L.J., Clark, G., Walker, M., Whyatt, J.D. 2013. It's just like an extra string to your bow': exploring higher education students' perceptions and experiences of extracurricular activity and employability. Act. Learn. High Educ., 14 (2) (2013), pp. 135-147.

4. Pereiraa, A.H., Ismail, K. and Othman, Z. 2012. A Model for the Malaysian English Language Club Activities.Procedia - Social and Behavioral Sciences 90 ( 2013 ) 48 - 56

5. Al Saleem, N., El Metwally, A. and Househ, M. 2014. Electronic Lab Information Exchange (ELIE) in Saudi Arabia. Integrating Information Technology and Management for Quality of Care. Medical Sciences Volume II J. Mantas et al. (Eds) IOS Press, 2014.

6. Hameed, S., Badii, A., Pervaiz, A., Mellor, J and Cullen, A. 2009. Impact of the e-learning package on the quality of student learning experience.Proceedings of the European and Mediterranean Conference on Information Systems, EMCIS 2009, pp. 1-15, 2009.

7. Bharamagoudar, S. R. 2013. Web-Based Student Information Management System. International Journal of Advanced Research in Computer and Communication Engineering, Vol.2, Issue 6, June 2013.

8. Chawla, S., Srivastava, S. and Bedi, P. 2017. Improving the quality of web applications with web specific goal driven requirements engineering.International Journal of System Assurance Engineering and Management. 2017; 8(1):65-77.

9. Panthi V., and Mohapatra, D.P. 2017. An approach for dynamic web application testing using MBT.International Journal of System Assurance Engineering and Management. 2017; 8(2):1704-16.

10. FauziHussin, Yahya Don, MohdSofian O. F., YaakobDaud, Arumugan a/l Raman, Ismail H. A. and Muhamadul B.Y. 2014. Co-Curricular Management Practices Among Novice Teachers In Malaysia. Asian Journal of Education and e-Learning (ISSN: 2321 - 2454) Volume 02 - Issue 02, April 2014.

11. Chi-Hung Leung, C-H, Raymond Ng, C. W and Ella Chan, P.O. 2011. Can Co-curricular Activities Enhance the Learning Effectiveness of Students? An Application to the Sub-degree Students in Hong Kong. International Journal of Teaching and Learning in Higher Education 2011, Volume 23, Number 3, 329-341

12. Patnaik, S. 2016. College Management System. International Research Journal of Engineering and Technology, Vol.3, Issue 5, May-2016.

13. Datakar, K. 2016. Online College Management System.International Journal of Computer Science and Mobile Computing, Vol. 5, Issue 4, April 2016.

14. Joshi, L. 2015. A Research Paper on College Management System. International Journal of Computer Applications, Vol.122, Issue 11, July 2015.

15. Babaei, M. and Beikzad, J. 2013. Management information system, challenges and solutions.European Online Journal of Natural and Social Sciences 2013.vol.2, No. 3(s), pp. 374-381 ISSN 1805-3602.

16. Kalimullah, K. and Sushmitha, D. 2017. Influence of design elements in mobile applications on user experience of elderly people. Procedia Computer Science.2017; 113:352-9.

17. Hui SL, See SL. 2015. Enhancing user experience through customization of UI design.Procedia Manufacturing. 2015; 3:1932-7.

18. Mambile, C., Machuve, D. and Moebs, S. 2018. User experience of a web-based platform for poultry market linkages in Tanzania. International Journal of Advanced Technology and Engineering Exploration, Volume-5, Issue-49, Dec2018, pp.495-503.DOI:10.19101/IJATEE.2018.547031

19. Kusyama SL, Machuve D, Kisangiri M, Mfanga A. 2020. Participation-reputation based incentive game model (PRIGM) for trustworthy fisheries information collection and dissemination framework. International Journal of Advanced Technology and Engineering Exploration. 2020; 7 (70): 137-146. DOI:10.19101/IJATEE.2020.762060

20. Al-Ansari, A., Al-Harbi, F., AbdelAziz, W., Abdel Salam, M., el Tantawi, M. and El Refae, I. 2016. Factors affecting student participation in extra-curricular activities: A comparison between two Middle Eastern dental schools. The Saudi Dental Journal (2016) 28, 36-43.

21. R. B. France, S. Ghosh, T. Dinh-Trong and A. Solberg. 2006. Model-driven development using UML 2.0: promises and pitfalls. Computer 39(2): 59-66. 